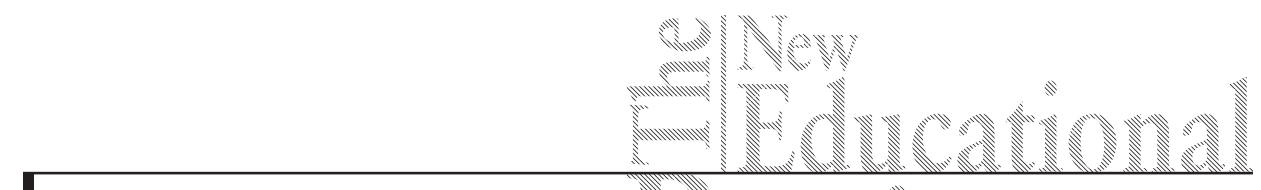

Boža D. Miljković, Aleksandar V. Petojević, Mališa R. Žižović

Serbia

\title{
On-line Student Emotion Monitoring as a Model of Increasing Distance Learning Systems Efficiency
}

DOI: 10.15804/tner.2017.47.1.18

\begin{abstract}
Modern concepts of education are increasingly focused on e-learning and distance learning. Expectations from them are at least the same efficiency, but also results higher than those obtained by the traditional education system. In distance learning systems the modules of assistants (tutors, helpers) are very important. They provide immediate feedback both to the student and the distance learning system. Tracking and recognizing emotions in distance learning systems is of great importance, especially in the adaptive capacity of automated education systems towards the student, but also in a corrective role in the distance learning process itself. Here we present a model for evaluating students based on automatic recognition of emotions during task solving.
\end{abstract}

Keywords: distance learning, entropy, emotion intensity, homogeneity

\section{Introduction}

Psychologists have redefined human intelligence shifting from cognitive intelligence as the central point of gravity to the inevitable inclusion of emotional intelligence (Goleman, 1995). Emotional intelligence is present in every communication process, and information about emotional states in human-computer interactions is especially analysed because it is the key link in achieving maximum efficiency (Picard \& Cosier, 1997). 
Methodological approaches to such knowledge transfer must be adjusted to indirect interaction, lack of a defined physical space, temporal distance and physical or visual contact. Many of the methodological and pedagogical approaches are entirely based precisely on these facts.

In this sense, emotional state analysis in education in the contemporary information and communication technologies (ICT) environment is not only required, but necessary. It is needed to compensate for negative effects, and to use positive ones in further learning. Emotional state plays an important role in decision making, problem solving, communication and negotiation. Therefore, recognition of emotions is necessary for the development of intelligent interactions between poeople and computers (Jacobs, 2005).

\section{Theoretical Background}

Emotional Speech Recognition (ESR) aims at automatic identification of the emotional state of the individual based on an analysis of their speech (Delić \& Sečujski, 2008). Emotions in speech are expressed via varying speech characteristics by level through specific frequency, intensity and duration, changes in articulation quality, general voice quality, amplitude, and frequency (Jovičić, Kašić, Đorđević, Vojnović, Rajković, Savković, 2003). In man-machine dialogue, the machine manages to communicate successfully by following users' reactions with ESR algorithms, recognizing key words and semantics in their answers and their level of satisfaction (Bojanić \& Delić, 2009).

We distinguish two types of emotions based on their origin: internally generated emotions which directly result from the interaction with the system and externally generated emotions that have their origin outside the system (Ochs \& Frasson, 2004). Positive emotions developed during the educational process have a strong, twofold positive impact on learning. Firstly, they allow for creative and flexible processes of thinking, and also increase motivation, so students try harder rather than give up. Secondly, students consciously want to maintain and possibly increase the intensity of positive emotional states, which maintains the levels of concentration and motivation for learning.

Algorithms of speech recognition technology and video analysis via analyzing the characteristics of voice, gestures and miming are used for identifying several emotional states: joy, sadness, fear, anger, surprise and disgust $(j, s \mathrm{~d}, f, a, s \mathrm{p}$ and d) (Busso, Deng, Yildirim, Bulut, Lee M.C., Kazemzadeh, Lee S., Neumann, Narayanan, 2004). During research, the occurrence of neutral emotional states 
Figure 1. Functional model of the machine in the verbal dialogue (Bosch, 2003)

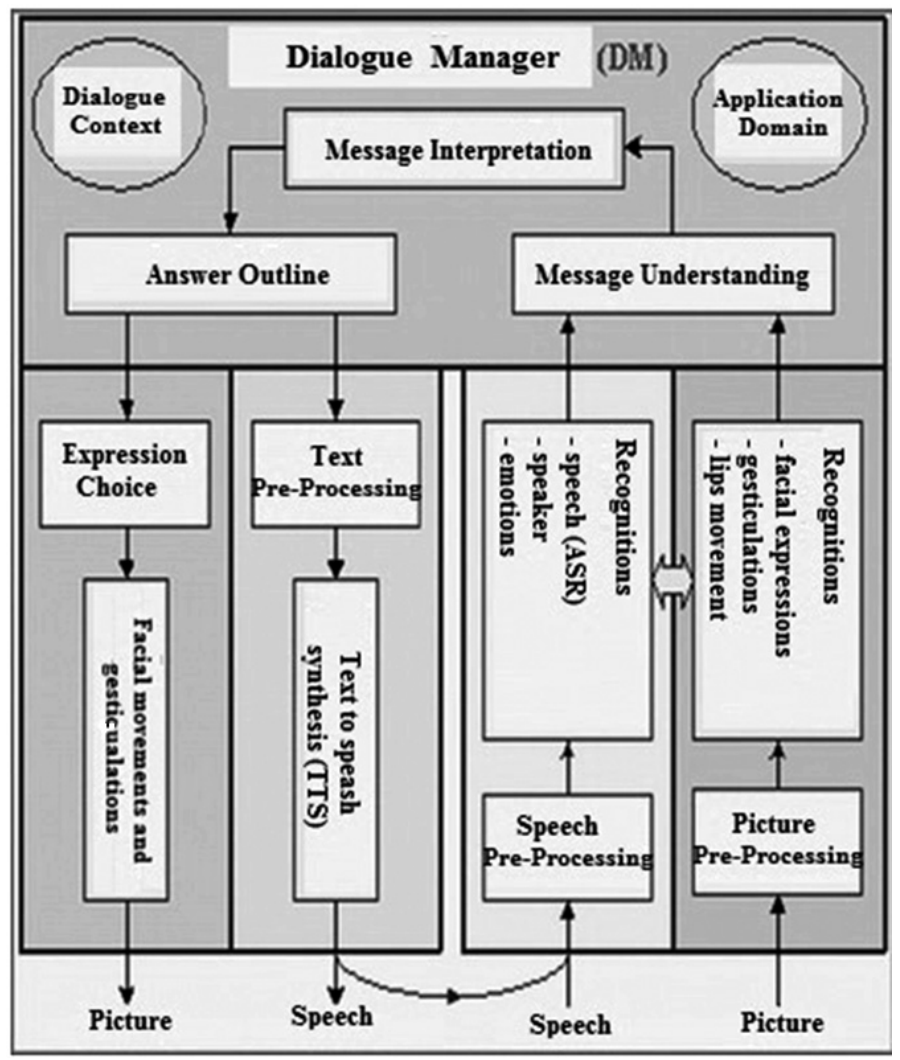

was often identified. According to the occurrence which characterizes neutral emotional states, it is treated as a type of emotion with a positive impact on learning. Individual changes in emotional intelligence correlate with emotional states. Emotional intelligence (in addition to cognitive intelligence) is a very important factor in learning. Emotional intelligence positively correlates with job satisfaction and negatively with depersonalization (Przybylska, 2016).

There can often be specific differences in the way that every individual receives information and gives it sense and meaning before it becomes a part of their everyday life (Yilmaz-Soylu \& Akkoyunlu, 2006). By making the assessment of the necessary correction, based on feedback, ICT encourages the desired behavior in learning, making it possible to design lectures that lead to success regardless of the environment. That way, students are given the opportunity to make cor- 
rections and clear up misconceptions and prejudice (Anohina, 2007). Emotions management contributes to professional effectiveness: in achieving academic goals, building quality social relationships, and maintaining a good classroom environment and discipline practices (Sutton, 2004).

Initial motivation is very important when approaching a course as well as learning whether the student joined the course due to intellectual curiosity or just as a means to obtain a diploma. Students often see lectures as an activity they are required to attend. Furthermore, they see their tasks as a curriculum that is supposed to be accomplished and eventually evaluated (Brophy, 2013). Automated education systems must avoid formalism during studies and solve problems without absolute understanding of such. This kind of system, except for evaluation-reward system, must also possess a guidance system, i.e., a system for simplifying and segmenting problems with adequate explanations and demonstrations (Nipkow, 2012).

\section{Research Methodology}

The research was conducted following the model shown in Figure 2. This model was designed to adjust services according to students' current needs. "Reasoning" and "determining" the algorithm of compensating for emotional states are reduced to a few steps:

1. Searching for solutions in the knowledge base according to statistics for the current environment and implementing the plan for the expected state and intention.

2. Emotions analysis and determining values (type and gradation)

3. Choice of presentation methodology (type of tutor or living agent)

4. Monitoring emotions changes and adjusting the presentation to new circumstances

5. Testing with monitoring emotional changes and correlation with the presented knowledge

6. Presentation of test results with an explanation based on recognised emotions

7. Selecting and offering an adequate tutoring system for possible corrections or advancing knowledge

8. Scenario backup.

During the exploitation of the DL system, the database of emotional algorithms and states of student emotions will continually be upgraded. Analyzing patterns through timelines, the type and intensity of students' emotional states, obtained 
Figure 2. Algorithm data flow in an automated DL system, expanded with a module for ESR

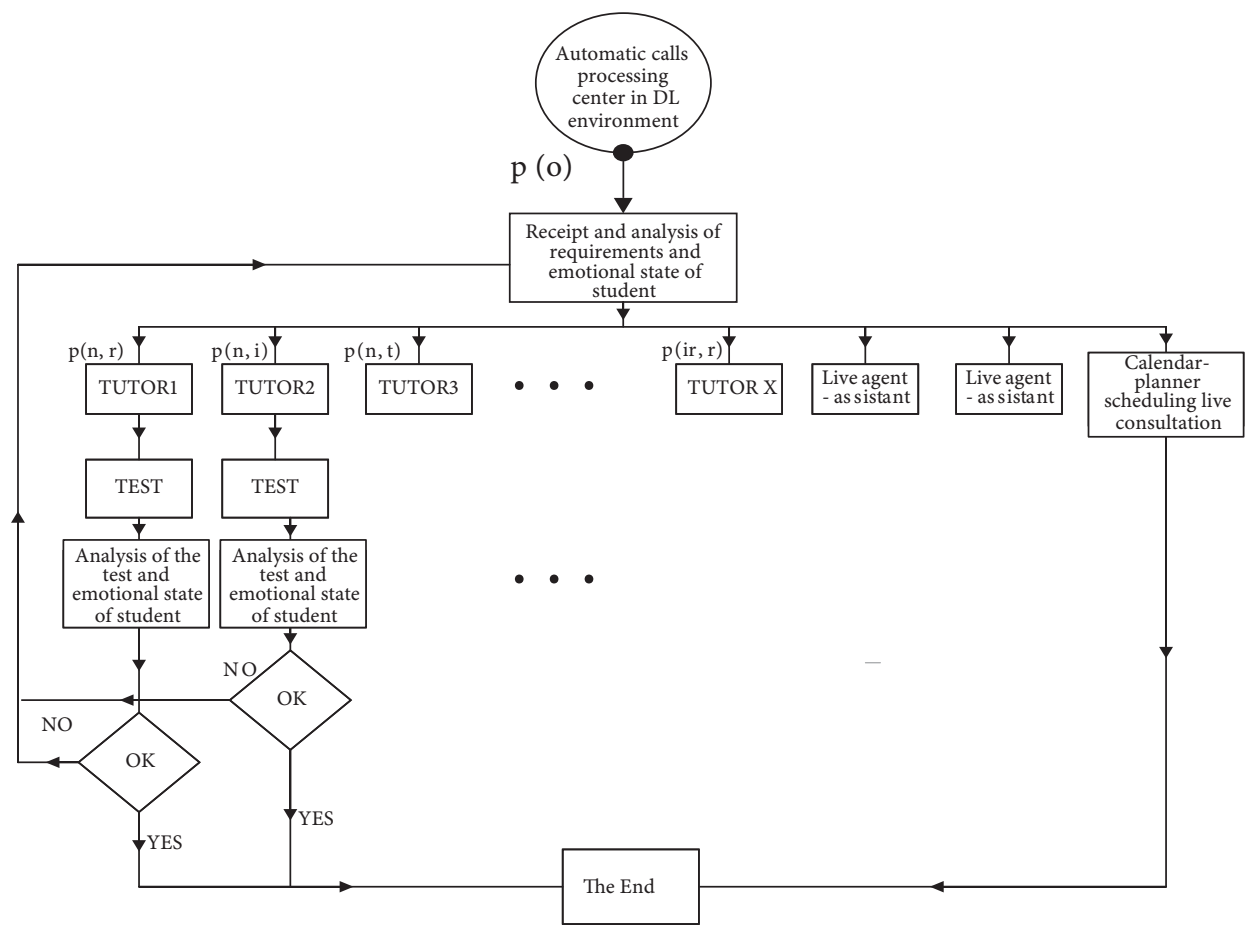

results and goals, the system will have information about the events, i.e., which emotional changes preceded the successful completion of tasks. If the student achieves targets $\mathrm{B}$ and $\mathrm{C}$, but fails to achieve target $\mathrm{A}$, the system must compare the type and intensity of emotions which were present at that moment, so that it can create an algorithm of a successful scenario as an alternative to failure. In the knowledge base, the system also contains phase algorithms. If the goal is hardly feasible, interphases are sought. Those interphases will ensure the successful implementation of training programs, i.e., through realizing targets $\mathrm{B}$ and $\mathrm{C}$ in a certain period of time, it is expected that target A will also be realized.

An "intelligent and adaptive" system of DL was simulated. This automated centre had a built-in algorithm for a multi-criterion approach to identifying students' emotional state and emotional intelligence. Thus, ITC and ALE (Adaptive Learning Environment) are created. This is an intelligent environment adapted to 
students' individual characteristics (Wenger, 1987; Cerri, Clancey, Papadourakis, Panourgia, 2012; Guin \& Lefevre, 2013).

The research builds upon analyses of distance consultation recordings during the course carried out by the improvised automated centre of DL through monitoring:

- changes in the type and intensity of emotional states

- reactions to new tasks and problems, change in dynamics in regards to the number of calls and call duration

- tracking homogeneity of the call and the positive and negative emotions

- development of a sense of security

- trends (number of calls, development of emotions, changes in the intensity of emotions, results obtained during the course, etc.)

- success in learning and solving problems

- homogeneity of results obtained during the course

- comparison between results obtained during the course and the level of prior knowledge.

The flow of education during the course was divided into thematic sections. Each thematic unit was developed through several stages. The process of solving tasks was divided into several segments:

1. Segment of introducing a problem, understanding and task analysis

2. Segment of solving a task

3. Segment of checking results and discussing solutions.

The research sample is represented by a group of first year students of undergraduate studies, study program New Media Design in Education. Each student is associated with a number of points, where a maximum of 100 points is defined for the level of prior knowledge. Previously passed exams (i.e., success in high school for "freshmen") are scored with a maximum of 40 points, and 16 points are considered as a minimum, $16 \leq \mu p \leq 40$. The entrance test (i.e., success in the previous year of study) is scored in a similar way, $0 \leq \mu p \leq 60$. We calculate the average level of prior knowledge $\bar{Z}$, for the entire class of $n$ number of students, where $Z_{k}$ is the number of starting points for each student.

The group was divided into two parts which were approximately equal in the amount of the average prior knowledge and homogeneity of prior knowledge: a group which could use the simulated DL system, available 24/7, and a group that acquired knowledge in a classical, traditional way (attending classes and if necessary consultations during office hours). We calculated the homogeneity of the whole group $h(S)$ and its subgroups $h\left(S_{1}\right)$ and $h\left(S_{2}\right)$, according to prior knowledge. Therefore, we formed the first group with $n_{1}$ students (experimental group) and 
the second group with $n_{2}$ students (control group). We calculated the $\bar{Z}_{\mathrm{I}}$ and $h\left(S_{1}\right)$ for the first group and $\bar{Z}_{\text {II }}$ and $h\left(S_{2}\right)$ for the second. $\bar{Z}_{\mathrm{I}} \sim \bar{Z}_{\mathrm{II}} \sim \bar{Z}$ was noted, but also $h\left(S_{1}\right) \sim h\left(S_{2}\right) \sim h(S)$. That is a condition that had to be fulfilled before comparing the quality and objectivity of the group results.

Table 1. Analysis of students' prior knowledge

THE STUDENTS ENROLLED IN THE FIRST YEAR OF STUDY, Course: NEW MEDIA DESIGN IN
EDUCATION

\begin{tabular}{|c|c|c|c|c|c|c|c|c|c|c|c|}
\hline$\dot{z}$ & $\begin{array}{l}\infty \\
0 \\
0 \\
0 \\
0 \\
0 \\
0 \\
0 \\
0 \\
0 \\
0 \\
1\end{array}$ & 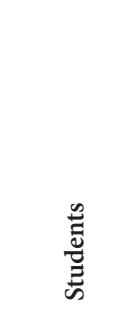 & 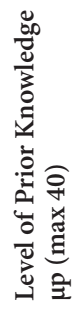 & 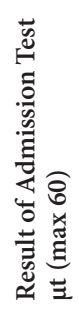 & 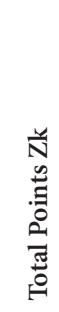 & 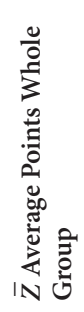 & 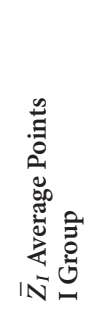 & 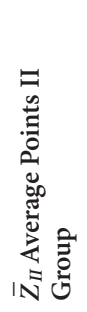 & $\underset{=}{\tilde{a}}$ & $\stackrel{\widehat{\omega}}{\widehat{c}}$ & 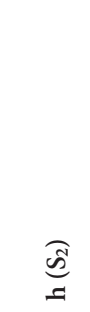 \\
\hline 1 & \multirow{6}{*}{ 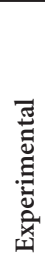 } & Student 1 & 30 & 44 & 74 & \multirow{15}{*}{65.80} & \multirow{6}{*}{69.17} & & \multirow{15}{*}{0.9553} & \multirow{6}{*}{0.9981} & \\
\hline 2 & & Student 2 & 32 & 43 & 75 & & & & & & \\
\hline 3 & & Student 3 & 32 & 36 & 68 & & & & & & \\
\hline 4 & & Student 4 & 33 & 31 & 64 & & & & & & \\
\hline 5 & & Student 5 & 16 & 44 & 60 & & & & & & \\
\hline 6 & & Student 6 & 34 & 40 & 74 & & & & & & \\
\hline 7 & \multirow{9}{*}{ 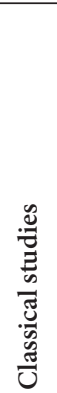 } & Student 7 & 32 & 47 & 79 & & & \multirow{9}{*}{63.56} & & & \multirow{9}{*}{0.9936} \\
\hline 8 & & Student 8 & 36 & 46 & 82 & & & & & & \\
\hline 9 & & Student 9 & 23 & 40 & 63 & & & & & & \\
\hline 10 & & Student 10 & 20 & 32 & 52 & & & & & & \\
\hline 11 & & Student 11 & 24 & 26 & 50 & & & & & & \\
\hline 12 & & Student 12 & 31 & 29 & 60 & & & & & & \\
\hline 13 & & Student 13 & 24 & 43 & 67 & & & & & & \\
\hline 14 & & Student 14 & 30 & 36 & 66 & & & & & & \\
\hline 15 & & Student 15 & 28 & 25 & 53 & & & & & & \\
\hline
\end{tabular}

\section{Research Hypotheses}

The following hypotheses were formulated:

H1: Adapting the learning environment in accordance with recognition of emotional states leads to greater achievements in the educational process. 
H2: Automated tutoring systems can actively manage the process of education in DL systems, regardless of the time and physical separation by analyzing the emotional states of DL system users.

\section{Research Results}

Homework was set for both groups, after completing the first of five sections. The homework was adjusted to every student and their prior knowledge. While doing homework, the students consulted the lecturer at least three times, i.e., at least once per segment during task solving. Each report represents a session which is terminated when a task or lectures are successfully absorbed, i.e., when they are understood and when positive emotions are generated in contact with the simulated DL centre. Apart from the defined mandatory calls, there may be optional calls and calls in order to settle a current dilemma, solution confirmation, etc. All these calls are ascertained in each segment by numbers, i.e.:

St1: task 1
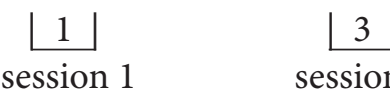

session 2

St2: task 1

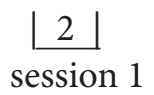

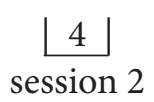
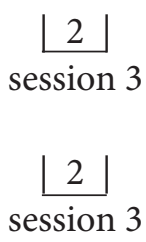
$\cdots$

When the system answered, a statement of emotions was determined, negative if present, and positive which were present after resolving the dilemma, at the end of session. The intensity of emotions for each student was determined (cf., Table 2). In our research, we planned five tasks which covered all topics of the teaching areas. Those tasks were divided into segments. We had 15 segments and measured the number of reports in each, e.g.:

\begin{tabular}{|l|l|l|l|l|l|l|l|l|l|l|l|l|l|l|}
1 & 3 & 2 & 2 & 4 & 2 & 2 & 2 & 3 & 4 & 4 & 2 & 2 & 2 & 2 \\
\hline 1 & 2 & 3 & 4 & 5 & 6 & 7 & 8 & 9 & 10 & 11 & 12 & 13 & 14 & 15
\end{tabular}

Based on the reports of segments, we can calculate homogeneity of reports for a particular student by the tasks $h\left(J_{Z}\right)$, and by the entire course $h(J)$. 
In the next step, we observe negative emotions which appear for each report. Negative emotions are denoted by $N_{i}$, and the degree of negative emotion by $q_{i}$, where $0.01 \leq q_{i} \leq 1$. Instead of using the value "zero" we used the term "almost zero" for negative emotions. The reason for this $\left(0.01 \leq q_{i}\right)$ was a phenomenon which can be called "discomfort of reporting", although the negative emotions were practically zero.

During the first task we get reports of negative emotions $N_{1}, N_{2}, \ldots, N_{k_{i}}$ and corresponding degrees $q_{1}, q_{2}, \ldots, q_{k i}$. Using this data we can calculate homogeneity of negative emotions $h\left(q_{z}\right)$. In the next step we observe negative emotions which appear for the second assignment. Inductively, we repeat this procedure until the last assignment is taken into account. Finally, we observe negative emotions for a student during the whole course $h(q)$.

Further, we observe positive emotions which appear for each report. Positive emotions are denoted by, $P_{i}$ and the degrees of positive emotion are denoted as $p_{i}$, where $0<p_{i} \leq{ }_{1}$. As with negative emotions, we examine reports of positive emotions $P_{1}, P_{2}, \ldots, P_{k_{i}}$ and corresponding degrees $p_{1}, p_{2}, \ldots, p_{k_{j}}$. Thus, we calculate homogeneity of positive emotions $h\left(p_{z}\right)$ i $h(p)$.

\section{Discussion}

The conclusions that are reached by analyzing the obtained data and the results obtained in the experimental group can be commented on in some of the following ways:

- if all students' negative emotions are of relatively low intensity and a high degree of homogeneity, tasks are set well

- if students' negative emotions are of high intensity in large numbers and a lower degree of homogeneity, some of the lectures and exercises are not clear, then such lectures and exercises must be adapted or clarified

- if negative emotions of the majority of students are of high intensity in large numbers and of a high degree of homogeneity, the tasks are not well set or lectures are not well designed

- if negative emotions among individuals are of high intensity in large numbers and of a high degree of homogeneity, the tasks are difficult and complicated for these students

- if positive emotions are of high intensity, negative emotions brought to a minimum, and the number of reports is minimal, tasks for the students 


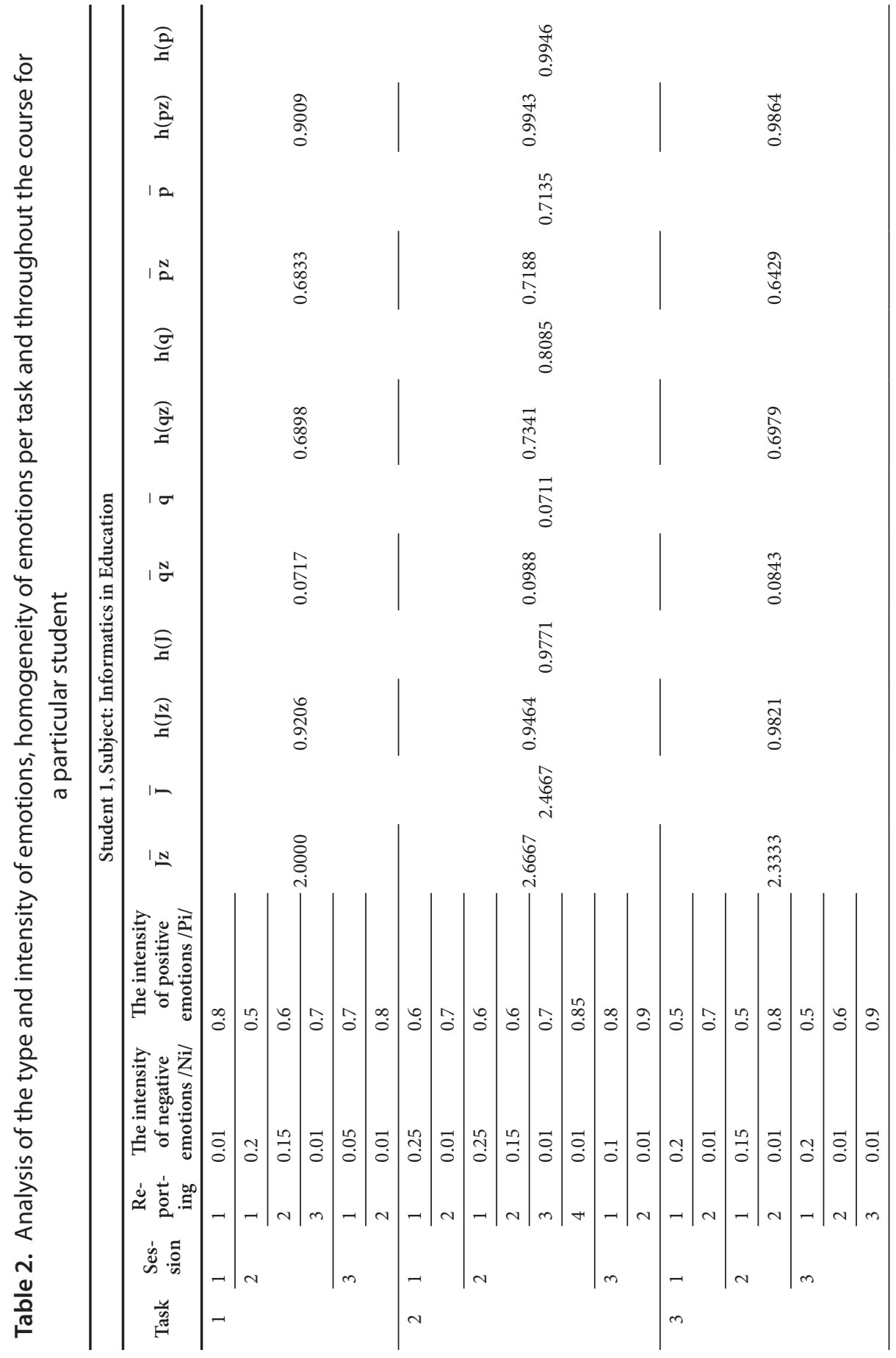




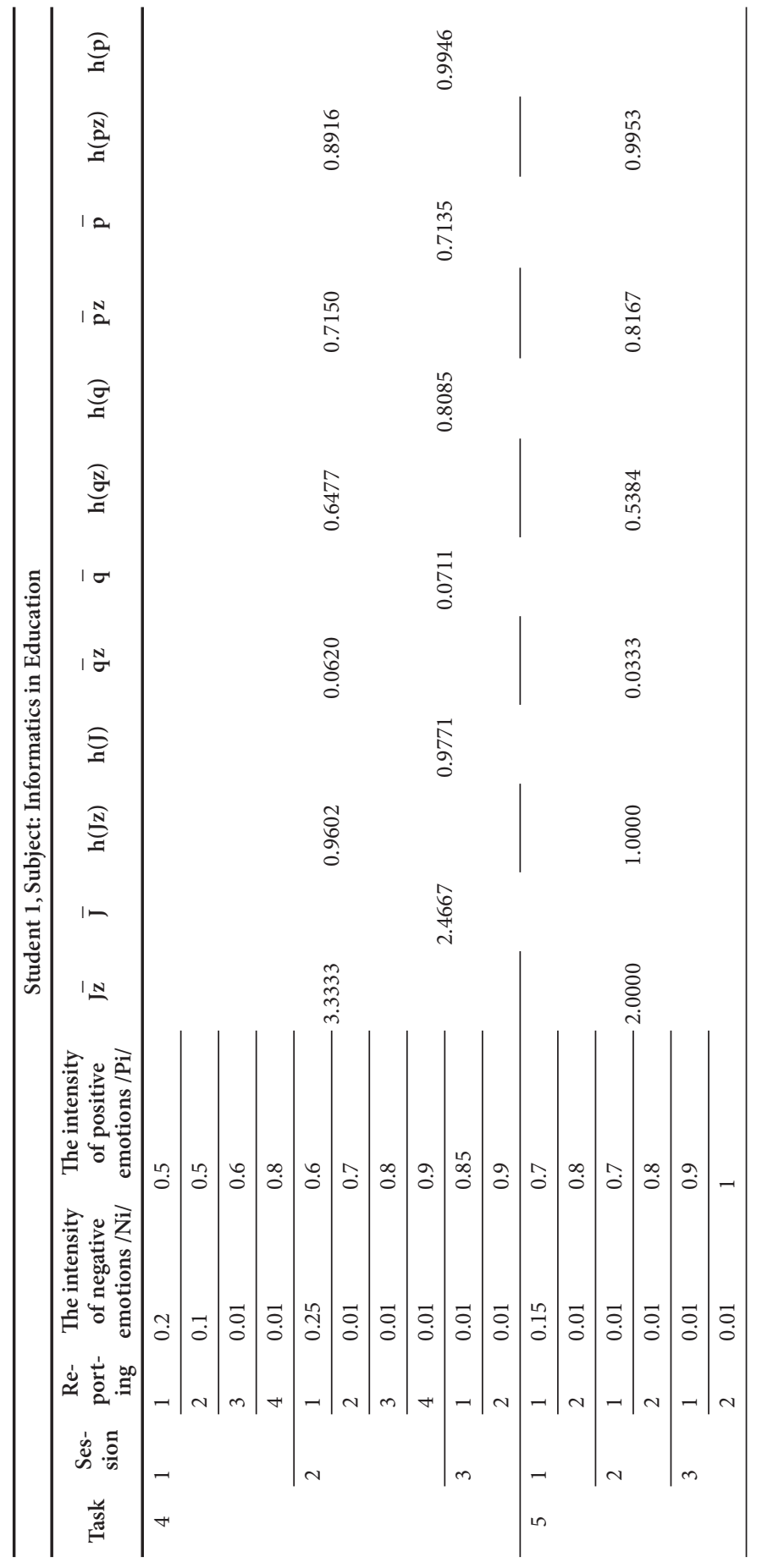


are trivial, and it is necessary to increase the complexity of tasks and adjust them to the abilities of an individual.

The next step was the actions of the system. After the first task, it is possible to make corrections in tasks or in presentations of the material. For each situation, the system must have an adequate response (scenario), but also an alternative scenario or satisfactory success. Corrective actions in terms of increasing or reducing the complexity of assignments and activating additional tutorials with examples and homework were conducted based on analysis of data after solving tasks. Corrective actions were specific and characteristic of each individual. In the case of student 6, who started the course with a high level of prior knowledge, after the first teaching area and the detection of a small amount of negative emotions and large amounts of positive emotions, the complexity of the tasks was increased in the second teaching unit. That caused the intensity of negative emotions to increase, whereas positive ones had remained at the same level. Therefore, in the next steps, the level of task complexity was maintained and monitored. Since the homogeneity of the number of calls was maintained and slowly increased, and the intensity of negative emotions was in a declining trend, we expected successful completion of the course with a high level of knowledge, and our expectations were confirmed.

Example of students 1, 3, 4 and 5: after the first action of the system, i.e., after the first correction and the increase in the difficulty of tasks, they responded with a significant increase in the number of calls to the system. Increase in the intensity of negative emotions was registered, which caused the increase in the length of the sessions, and the tackling of a higher number of examples and assignments. By engaging additional tutorials, the intensity of positive emotions was slowly rising chapter by chapter, while the homogeneity of calls was approaching the maximum, $h(J) \sim 1$.

Student 2 was a specific case, who made progress in relation to the level of prior knowledge, but not in the expected volume compared to the obtained results of other students in the experimental group. After the first correction of tasks, the reaction of this student was lacking. The number of calls did not change; it even decreased at some stages. Homogeneity of reports decreased and the intensity of negative emotions grew, while the homogeneity of emotions was variable and decreasing. The conclusion is that this was a superficial and binge approach to learning, where prior knowledge and knowledge "from memory", from lectures and exercises, were used in solving problems. We defined a special tutoring system for this student, which gave him tasks with additional reminders. 
In general, the students with a greater number of calls did more tasks and got a higher number of solved examples for analysis and discussion. In these cases, options of corrective actions were more varied, especially for those with high motivation.

Table 3. Results obtained at the end of the course (exam)

\begin{tabular}{|c|c|c|c|c|c|c|c|c|c|}
\hline \multicolumn{10}{|c|}{ Achievements of Students at Exam, Subject: Informatics in Education } \\
\hline No. & $\begin{array}{c}\text { Type of } \\
\text { Subgroups }\end{array}$ & Students & $\begin{array}{l}O \text { Test } \\
\text { Score }\end{array}$ & $\begin{array}{c}\bar{O} \\
\text { Average } \\
\text { Test } \\
\text { Score }\end{array}$ & $\begin{array}{c}\bar{O}_{I} \\
\text { Average Test } \\
\text { Score Group I }\end{array}$ & $\begin{array}{c}\bar{O}_{I I} \\
\text { Average Test } \\
\text { Score Group II }\end{array}$ & $h(S)$ & $h\left(S_{1}\right)$ & $h\left(S_{2}\right)$ \\
\hline 1 & \multirow{6}{*}{$\begin{array}{l}\text { Experi- } \\
\text { mental }\end{array}$} & Student 1 & 10 & \multirow{15}{*}{7.73} & \multirow{6}{*}{9.50} & & \multirow{15}{*}{0.9924} & \multirow{6}{*}{0.9992} & \\
\hline 2 & & Student 2 & 9 & & & & & & \\
\hline 3 & & Student 3 & 10 & & & & & & \\
\hline 4 & & Student 4 & 9 & & & & & & \\
\hline 5 & & Student 5 & 9 & & & & & & \\
\hline 6 & & Student 6 & 10 & & & & & & \\
\hline 7 & \multirow{9}{*}{$\begin{array}{l}\text { Classical } \\
\text { studies }\end{array}$} & Student 7 & 8 & & & & & & \multirow{9}{*}{0.9976} \\
\hline 8 & & Student 8 & 6 & & & & & & \\
\hline 9 & & Student 9 & 6 & & & & & & \\
\hline 10 & & Student 10 & 7 & & & & & & \\
\hline 11 & & Student 11 & 6 & & & 6.56 & & & \\
\hline 12 & & Student 12 & 7 & & & & & & \\
\hline 13 & & Student 13 & 6 & & & & & & \\
\hline 14 & & Student 14 & 7 & & & & & & \\
\hline 15 & & Student 15 & 6 & & & & & & \\
\hline
\end{tabular}

Based on Table 3, we can conclude that the homogeneity of the whole group is violated, i.e., the obtained results vary considerably. Since the homogeneity of both subgroups is high, it is concluded that the results of the subgroups are different. The high homogeneity of the subgroups shows that the students mastered the subject in a similar way and that they obtained similar results, depending on the mode of teaching. In this way, we exclude the significant negative impact of the teacher or methods of class implementation.

By comparing the data from the beginning of the course and the results which were obtained at the end of the course, it was found that almost all the students made progress. However, analysis of the results by subgroups shows that the experimental group obtained a result which was excellent, while the progress 
of the other group was poor. Since the levels of prior knowledge were similar, it can be concluded that the simulated automated centre with a built-in algorithm for a multi-criterion approach to identifying the emotional states and emotional intelligence of system users has successfully updated and personalized its delivery. The emphasis is put especially on the individual, since some students (4 and 5) made up for large holes in prior knowledge, by frequent use of the advantages of the automated centre.

Figure 3. Diagrams of prior knowledge levels and obtained results
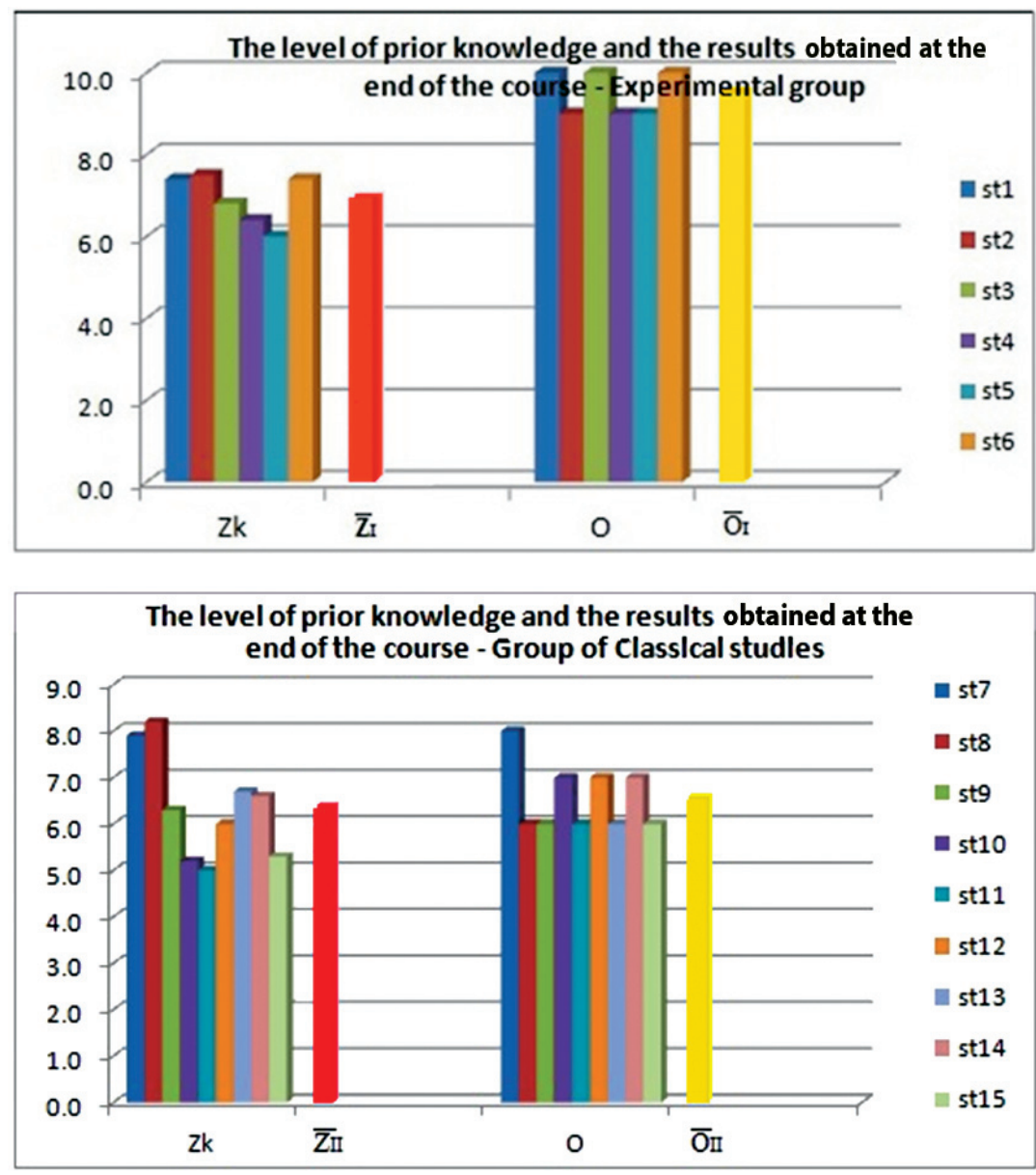


\section{Conclusion}

Upgrading the DL system with an algorithm for a multi-criterion approach to identifying emotional states and emotional intelligence of system users, fundamentally changes, modernizes and improves DL systems.

These kinds of systems operate in a temporal domain which is characterized by certain conditions of the environment. It is important to notice that these conditions change under the influence of lecturers, students, weather and seasonal conditions, as well as stressful conditions caused by emotional states of fear, anger, sadness, etc. As noted, besides the analyser and compensators for emotional states, the model establishes a knowledge base of emotional states and algorithms for future actions based on emotional experiences, impressions, treatments and results in certain situations. Even if in certain situations the automated system does not have an adequate answer and cannot provide adequate service, the request is redirected to a "live" agent, and the live agent will have enough initial information (from the system) to be able to prevent unpleasant scenarios.

Feedback about emotional states and emotional intelligence greatly contributes to the quality and success of achieving educational goals. This is especially important for DL education systems with no direct interaction and communication with teachers, as it provides autonomy to the DL system.

\section{References}

Anohina A. (2007). Advances in Intelligent Tutoring Systems: Problem-solving Modes and Model of Hints. International Journal of Computers, Communications \& Control Vol. II No. 1, (pp. 48-55).

Bojanić M. \& Delić V. (2009). Automatic emotion recognition in speech: possibilities and significance, Conference INFOTEH-JAHORINA, Vol. 8 Ref. B-III-8, (pp. 223-227).

Bosch L. (2003). Emotions, speech and the ASR framework, Speech Communication 40, (pp. 213-225).

Brophy J. (2013). Motivating students to learn. New Jersey: Routledge.

Busso C., Deng Z., Yildirim S., Bulut M., Lee M.C., Kazemzadeh A., Lee S., Neumann U., Narayanan S. (2004). Analysis of Emotion Recognition using Facial Expressions, Speech and Multimodal Information. The $6^{\text {th }}$ international conference on Multimodal interfaces, ICMI ‘04. (pp. 205-211).

Cerri S., Clancey W., Papadourakis G., Panourgia K.K. (2012). Intelligent Tutoring Systems, Intelligent Tutoring Systems: Proceedings of the $11^{\text {th }}$ International Conference, Vol. 7135. (pp. 1-10). Crete, Greece: Springer-Verlag Berlin Heidelberg.

Delić V. \& Sečujski M. (2008). Transakcioni model verbalne interakcije čovek-mašina 
(Transactional Model of Human-Machine Speech Interaction), Conference DOGS, Kelebija, (pp. 8-15).

Goleman D. (2005). Emotional Intelligence, The $10^{\text {th }}$ Anniversary Edition, New York: Bantam Books.

Guin N. \& Lefevre M. (2013). Artificial Intelligence in Education, Artificial Intelligence in Education: Proceedings of AIED 2013, Vol. 7926. (Eds.) Lane H., Yacef K., Mostow J., Pavlik P., Memphis TN, USA: Springer Berlin Heidelberg.

Jacobs D.C. (2005). The Application of Informal Feedback Intervention as a Communication Management Tool in Learning Organisations, Doctoral Thesis, University of Pretoria.

Jovičić S.T., Kašić Z., Đorđević M., Vojnović M., Rajković M., \& Savković J. (2003). Formiranje korpusa govorne ekspresije emocija i stavova u srpskom jeziku-GEES (Creation of a Corpus of Speech Expression of Emotions and Attitudes in the Serbian Language), XI Telekomunikacioni forum TELFOR, Beograd.

Nipkow T. (2012). Teaching Semantics with a Proof Assistant: No More LSD Trip Proofs. Viktor Kuncak \& Andrey Rybalchenko, (Eds.) VMCAI Verification, Model Checking, and Abstract Interpretation, Philadelphia, USA, Springer (pp. 24-38).

Ochs M. \& Frasson C. (2004). Optimal Emotional Conditions for Learning with an Intelligent Tutoring System, J.C. Lester et al. (Eds.), ITS 2004, LNCS 3220 Springer-Verlag Berlin Heidelberg, (pp. 845-847).

Picard R.W. and Cosier G. (1997). Affective intelligence - the missing link?, BT Technology Journal, Vol. 15 No 4. (pp. 151-162).

Przybylska I. (2016). Emotional Intelligence and Burnout in the Teaching Profession, The New Educational Review, Vol. 43 No 1, Wydawnictwo Adam Marszałek, Toruń (pp. 41-53).

Sutton R.E. (2004). Emotion regulation goals and strategies, Social Psychology of Education 7, (pp. 379-398).

Wenger E. (1987). Artificial intelligence and tutoring systems: Computational and Cognitive Approaches to the Communication of Knowledge, San Francisco, CA, USA : Morgan Kaufmann Publishers Inc.

Yilmaz-Soylu M. \& Akkoyunlu B. (2009). The effect of learning styles on achievement in different learning environments. The Turkish Online Journal of Educational Technology $8(6)$. 